\title{
Reflexões e Perspectivas acerca da Construção do Conhecimento sobre Empreendedorismo Interno
}

\author{
Magnus Luiz Emmendoerfer ${ }^{1}$ \\ Josiel Lopes Valadares ${ }^{2}$
}

\section{Resumo}

Resultado de uma pesquisa no Brasil sobre "a construção do conhecimento em empreendedorismo: um levantamento teórico-reflexivo", este metaestudo tem como enfoque o empreendedorismo interno. O objetivo do trabalho é levantar a produção científica sobre empreendedorismo interno nas organizações em eventos especializados no Brasil na área de administração, no período de 1997 a 2007, a fim de identificar a construção do conhecimento e as perspectivas emergentes de pesquisa sobre esse enfoqueno campo. Como objetivo complementar procurou-se também identificar, na produção científica mencionada e selecionada, as características do comportamento empreendedor interno.Fez-se uso de princípios de meta-análise e da técnica de análise de conteúdo. Dentre os resultados principais, percebe-se,como reflexões necessárias no campo, a necessidade de clarificação dos elementos que distinguem os empreendedores corporativos dos intraempreendedores nas organizações. Como perspectivas futuras de investigação, há um vasto campo para explorar em termos teóricos e empíricos as singularidades da manifestação nas organizações contemporâneas do empreendedorismo interno no Brasil e em perspectiva comparada.

Palavras-chave: Meta Análise. Intraempreendedorismo. Empreendedorismo Corporativo.

\footnotetext{
1Doutor em Ciências Humanas: Sociologia e Política pela Universidade Federal de Minas Gerais-UFMG. Professor do Programa de Pós-graduação em Administração (PPGAdm) do Departamento de Administração e Contabilidade da Universidade Federal de Viçosa-UFV. End.: Av. P.H. Rolfs, s/n, Campus Universitário, Viçosa-MG. CEP:36570-000-Brasil.E-mail: magnus@ufv.br.

${ }^{2}$ Mestrando em Administração pelo Programa de Pós-Graduação em Administração (PPGAdm) da Universidade Federal de Viçosa - UFV. End.: Av. P.H. Rolfs, s/n, Campus Universitário, Viçosa-MG. CEP: 36570-000-Brasil.E-mail: adm_josiel@yahoo.com.br.

Artigo recebido em: 19/04/2010. Aceito em: 07/04/2011. Membro do Corpo Editorial Científico responsável pelo processo editorial: Rolando Juan Soliz Estrada. 


\section{Introdução}

As mudanças ocorridas no mercado, nos últimos anos, têm provocado algumas ponderações acerca do desenvolvimento do espírito empreendedor nas organizações. Câmpelo e Almeida (2007) observam que a literatura em ciências administrativas tem convergido num debate que enfoca o empreendedor nas organizações, não na condição de empresário ou criador/ fundador do negócio, mas sim comoempregado ou stakeholder imerso nelas. Eis o empreendedor interno, objeto de estudo neste artigo.

O termo empreendedorismo interno, apesar de ser encontrado na literatura popular de negócios (pop-management) em reportagens, em notícias de revistas e em portais eletrônicos da área de administração, não é um termo comumente encontrado da produção científica brasileira (EMMENDOERFER et al., 2008). Pressupõe-se neste artigo que o termo empreendedorismo interno (indoor entrepreneurship) seja um rótulo também ausente ou pouco frequente na literatura especializada existente em periódicos científicos estrangeiros. Argumenta-se que a ausência, ou a baixa frequência, desse termo no Brasil e no exterior seja causada pela ênfase atribuída na literatura de administração a temas relacionados ao comportamento organizacional e não necessariamente ao empreendedor nas organizações. E quando se encontra esse termo, o empreendedor nas organizações é evidenciado como intraempreendedor ou empreendedor corporativo (EMMENDOERFER et al., 2010).

Nesse sentido, o objetivo deste meta-estudo é levantar a produção científica sobre empreendedorismo interno em eventos especializados na área de administração no Brasil, no período de 1997 a 2007. Como objetivo complementar procurou-se também identificar, na produção científica nacional, as características do comportamento do empreendedor interno.

$\mathrm{O}$ termo empreendedorismo interno refere-se neste artigo às atitudes e aos comportamentos tomados por indivíduos - na condição de empregados - dentro de uma organização e foi utilizado como um recurso metodológico para discutir e congregar a produção sobre os eixos temáticos "Intraempreendedorismo" e "Empreendedorismo Corporativo" que foram tratados como sinônimos para fins desta pesquisa. Entretanto, deve ser ressaltado, que em termos conceituais, existem particularidades entre esses dois eixos temáticos, portanto, torna-se importante conhecê-los. 


\section{Empreendedorismo Corporativo}

O termo empreendedorismo foi mencionado pela primeira vez por Richard Cantillon, em 1755, com o objetivo de explicar a receptividade ao risco de comprar algo por um preço e vendê-lo em regime de incerteza. A partir disso, os estudiosos Jean Baptiste Say e Joseph Schumpeter buscaram compreender mais acerca do construto do empreendedorismo (HASHIMOTO, 2006), com intuito de alcançar um maior nível de informações, dada a amplitude do termo empreendedorismo para a ciência. Para introduzir um dos eixos temáticos deste trabalho, menciona-se Cuninghan e Lischeron (1991) proponentes da escola corporativa, que valorizam as habilidades empreendedoras como cariáveis úteis para organizações complexas (HASHIMOTO, 2006).

Hashimoto (2009) destaca que os primeiros estudos sobre essa escola que trata do empreendedorismo corporativo datam de 1970 com os trabalhos de Peter Drucker e Arnie Cooper. Para Drucker, a responsabilidade das empresas existentes do ponto de vista empreendedor, sobretudo para empresas já bem-sucedidas, é manter-se bem-sucedida no futuro, suas ideias ganharam força na década de 1980, quando as empresas japonesas começaram a invadir o país com seus produtos mais baratos e de melhor qualidade. A partir desse momento houve um interesse crescente de pesquisadores no estabelecimento de relações entre empreendedorismo e corporações gerando várias terminologias ao longo do tempo, conforme Tabela 1:

Tabela 1: Terminologias do Empreendedorismo Corporativo relacionáveis ao Empreendedorismo interno

\begin{tabular}{|c|c|c|}
\hline Autores & Ano & Terminologia \\
\hline Cooper & 1981 & Empreendedorismo intracorporativo \\
\hline Schollhammer & 1981 & Empreendedorismo corporativo interno \\
\hline Miller & 1985 & Orientação Empreendedora \\
\hline Khandwalla & 1987 & Gestão inovadora pioneira \\
\hline Ellis \& Taylor & 1987 & Corporate Venturing \\
\hline Sathe & 1989 & Renovação organizacional \\
\hline Stevenson \&Jarillo & 1990 & Gestão Empreendedora \\
\hline Morse & 1996 & Empreendedorismo em nível de empresa \\
\hline Dess, Lumpkin\&Covin & 1997 & Estratégia empreendedora \\
\hline Birkinshaw & 1997 & Alianças corporativas \\
\hline
\end{tabular}

Fonte: Hashimoto (2009, p. 90) 
As denominações apresentadas anteriormente possibilitam caracterizar o empreendedorismo interno. Esse termo torna-se evidente quando os proprietários ou dirigentes da organização estimulam o engajamento de funcionários em atividades internas direcionadas para o desenvolvimento de sua estruturapor meio de pequenas unidades independentes dentro da organização (ZAHRA, 1991; FERREIRA, 2001). Muitas vezes, os resultados desse engajamento refletem em inovações concretas para as organizações, sendo que, tais inovações podem abranger produto, processo e ações administrativas em vários níveis da organização (BURGELMAN; SAYLES, 1986).

O empreendedorismo corporativo se baseia em três premissas importantes que são a inovação, a autonomia e a propensão a tomar riscos (LONGENECHER; SCHOEN, 1975). Percebe-se que essas características são de certa forma análogas às do comportamento de empreendedores. Isso mostra que a diferença entre empreendedor e empreendedor corporativo reside no fato do segundo ter seu ambiente de atuação moldado pelas normas ou pelas regras da organização em que está inserido. No entanto, Miller (1985) trocou o componente "autonomia"pelo componente"pró-atividade", com a justificativa de implementar o que for necessário para antecipar e agir sobre uma oportunidade empreendedora com perseverança, adaptabilidade e tolerância a riscos. O estabelecimento dessas variáveis serviu de base para definir o construto orientação empreendedora, o conjunto de processos-chave, as práticas $e$ as atividades de tomada de decisão que levam as organizações a empreenderem novos negócios (LUMPKIN; DESS, 1996), e é constituído pelas dimensões de inovação, autonomia, pró-atividade, propensão a assumir riscos e agressividade (COVIN; COVIN, 1990).

Normalmente, o empreendedor corporativo faz parte de organizações que são caracterizadas como holdings ou corporações no âmbito regional, nacional e internacional, atuando como gestor de Unidades Estratégicas de Negócios (UEN), ele faz parte do alto escalão das organizações, isto é, ele trabalha na alta administração podendo ser representante dos acionistas em conselhos administrativos, consultores e especialistas da área de gestão empresarial, planejamento estratégico e desenvolvimento de novos negócios que enfrentam a decisão de estabelecer a diferença ou não nos seus negócios (SEIFFERT, 2005; CHIEH; ANDREASSI, 2007; EMMENDOERFERet al.,2008). Nesse ínterim, o empreendedor corporativo busca oportunidades presentes no ambiente mercadológico para que sejam desenvolvidas inovações no que tange ao estabelecimento de novos negócios ou de um novo 
posicionamento no mercado, fazendo assim com que ele possua uma grande propensão a correr riscos calculados. Dado a autonomia para tomar decisões, o empreendedor corporativo incorre no risco de não conseguir gerar resultados na sua UEN, podendo gerar um prejuízo grande para a empresa e, dessa maneira, perder seu próprio emprego. Assim, o empreendedor incorre em riscos empresariais e profissionais (EMMENDOERFER; VALADARES; HASHIMOTO, 2010).

\section{Intraempreendedorismo}

O primeiro estudo encontrado no Brasil sobre o intraempreendedorismo foi publicado por Gifford PinchotIII em 1985 com o título Intrapreneuring. O intraempreendedor é caracterizado pela busca de seu crescimento pessoal/ profissional, por meiodo desenvolvimento de novos produtos, processos $e$ procedimentos de trabalho (HISRICH;PETERS, 2004). Para que esse indivíduo consiga se realizar no ambiente das organizações, ele deve ser incitado a desenvolver competências empreendedoras que o tornam um empreendedor inserido na estrutura da organização. Essas competências estão relacionadas ao desejo de autorrealização; se o indivíduo é criador ou inventor que planeja transformar ideias em oportunidades dentro da organização; se é um profissional que quando recebe a devida liberdade, incentivo e recursos procurasededicar arduamente em converter ideias em produtos ou processos (PINCHOT III, 1985). Percebe-se que se o intraempreendedor obtiver espaço para que suas ideias sejam realizadas e sua criatividade seja levada em consideração, ele tende a se tornar um agente de mudanças em seu espaço de trabalho, pois, sua busca constante por crescimento profissional/carreira culminará em resultados vantajosos para a organização, gerando uma maior satisfação para os stakeholders. Do ponto de vista da empresa, o intraempreendedorismo acontece quando atitudes individuais são valorizadas, não necessariamente por meiode processos formais (EMMENDOERFER et al., 2010).

Stevenson e Jarillo (1990) definem intraempreendedorismo como empreendedorismo em empresas existentes, a partir de um processo no qual os indivíduos dentro das organizações perseguem oportunidades independentemente dos recursos que controlam. Nicholas (1993) prefere abordar a morfologia da palavra intraempreendedorismo, segundo a qual "intra" signi- 
fica "dentro", "pre" significa "antes" e "neur" significa "centro nervoso", ou seja, a mudança substancial do centro nervoso do negócio. Pryor e Shays (1993) evidenciam que o intraempreendedorismo é a criação de um ambiente no qual a inovação pode florescer de forma a transformar pessoas comuns em empreendedores de sucesso. Chung e Gibbons (1997) explicam que o intraempreendedorismo se dá pela transformação de ideias individuais em ações coletivas por meiodo gerenciamento de incertezas. A empresa constrói estruturas e clima organizacional que apoiem e desenvolvam a inovação internamente, estimulando o funcionário a se comportar como dono do negócio. Dessa forma, percebe-se que o intraempreendedorismo é um fator crucial para a efetividade da organização. Nesse sentido, as organizações que conseguem gerar um clima que permite a formação desses indivíduos alcançarão resultados mais satisfatórios.

Antonic e Hisrich (2001) defendem que o intraempreendedorismo é uma forma de explicar a revitalização do desempenho das empresas no nível organizacional, mas ressaltam que tal revitalização está condicionada a uma adequação dos objetivos organizacionais às aspirações pessoais dos funcionários. Jones e Butler (1992) vão mais a fundo e explicam que no intraempreendedorismo os funcionários identificam imperfeições criadas pelo desequilíbrio da distribuição de informações e agem para identificar oportunidades nessas imperfeições, obtendo vantagens financeiras ao explorar tais oportunidades. Com isso, observa-se que os objetivos dos intraempreendedores devem estar alinhados ao foco da organização para que haja uma orientação empreendedora.

Portanto, a principal diferença conceitual entre os termos intraempreendedorismo e empreendedor corporativo reside no horizonte de atuação em virtude da posição em que o indivíduo ocupa na organização. Enquanto o intraempreendedor tem como horizonte a inovação nos produtos, processos e procedimentos no interior da própria organização, o empreendedor corporativo tem o seu horizonte centrado no mercado, buscando desenvolver novas estratégias e negócios para a própria organização. Frente a isso, como estão sendo empregados esses termos na produção científica nacional em eventos especializados da área de Administração? 


\section{Procedimentos Metodológicos}

Como ponto de partida, os procedimentos metodológicos desta pesquisa tiveram como base norteadora o método meta-análise (ALBERNETHY; FRANKE, 1996; HUNT, 1997; EPSTEIN, 1998). Isso permitiu compor uma base de dados inicial para esta pesquisa constituída de 140 artigos publicados no campo com o termo "empreendedorismo", entre 1997 a 2007, em anais de oito eventos da Associação Nacional de Pós-Graduação e Pesquisa em Administração (ANPAD). A ANPAD é uma associação que desenvolve um consistente e reconhecido trabalho de mais de 35 anos dedicados à promoção do ensino, da pesquisa científica e da construção de conhecimento dentro do campo das Ciências: administrativa, contábeis e afins no Brasil, além de ser reconhecida internacionalmente. Isso justifica a escolha dessa fonte de dados nesta pesquisa.

Dos 140 artigos publicados, foram encontrados (e desconsiderados posteriormente para fins desta pesquisa) 88 artigos sobre esse mesmo assunto nos anais do Encontro da ANPAD (EnANPAD); 14 foram encontradosno Encontro de Estudos em Estratégia (3Es); dez, no Encontro de Ensino e Pesquisa em Administração e Contabilidade (EnEPQ); oito no Encontro de Administração Pública e Governança (EnAPG); oito, no Simpósio de Gestão e Inovação Tecnológica (SIMPÓSIO); seis, no Encontro de Estudos Organizacionais (EnEO); dois, no Encontro de Marketing da ANPAD (EMA); um, no Encontro de Administração da Informação (EnADI). Vale destacar que a ANPAD promove nove eventos diferentes, sendo que no evento Encontro de Gestão de Pessoas e Relações de Trabalho (EnGPR), cuja primeira edição foi em 1997, não foi identificado nenhuma publicação sobre empreendedorismo.

A partir dessa pré-seleção foi feita uma categorização temática que buscou dentre os artigos aqueles referentes ao tema empreendedorismo interno por meio dos termos ou eixos temáticos "intraempreendedorismo" $e$ "empreendedorismo corporativo", o que permitiu identificar 11 artigos nos eventos da ANPAD. Desses 11 artigos, cinco referem-se à intraempreendedorismo, e foram publicados: quatro no EnANPAD; e um noEnEPQ. Os seis artigos restantes referem-se ao empreendedorismo corporativo, sendo três publicados, no EnANPAD, dois no EnEO e um no Simpósio. 
Vale destacar que essa categorização temática também foi realizada, considerando o período da pesquisa, nas quatro primeiras edições (2000 a 2006) do Encontro de Estudos sobre Empreendedorismo e Gestão de Pequenas Empresas - EGEPE, evento específico no campo e organizado a cada dois anos por uma rede de pesquisadores de instituições de ensino superior no Brasil. Contudo, não foi identificada nenhuma publicação relacionada aos dois eixos temáticos supramencionados. Assim, a Tabela 2 apresenta o resultado sumarizado desse processo de levantamento, distribuídos por evento da ANPAD, em que se destacou (com negrito e itálico) os eventos e a quantidade de artigos, referentes aos dois termos de interesse desta pesquisa.

Tabela 2: Eventos, termos e quantidade de publicações no campo

\begin{tabular}{|l|c|c|c|c|}
\hline \multirow{2}{*}{ Evento } & \multirow{2}{*}{$\begin{array}{c}\text { Quantidade } \\
\text { total }\end{array}$} & Empreendedorismo & \multicolumn{3}{|c|}{ Distribuição de frequências por termo } \\
\cline { 3 - 6 } & & 88 & 4 & $\begin{array}{c}\text { Empreendedorismo } \\
\text { corporativo }\end{array}$ \\
\hline EnANPAD & 97 & 8 & 0 & $\mathbf{3}$ \\
\hline 3Es & 9 & 8 & $\mathbf{1}^{* *}$ & 0 \\
\hline EnEPQ & 8 & 8 & 0 & 0 \\
\hline EnAPG & 9 & 7 & 0 & 0 \\
\hline Simpósio & 7 & 7 & 0 & $\mathbf{1}^{* * *}$ \\
\hline EnEO & 7 & 2 & 0 & $\mathbf{2}^{* * * *}$ \\
\hline EMA & 2 & 1 & 0 & 0 \\
\hline EnADI & 1 & 129 & $\mathbf{5}$ & 0 \\
\hline Total & 140 & & $\mathbf{6}$ & \\
\hline
\end{tabular}

*Esse termo foi aplicado no levantamento dos artigos com hífen, intraempreendedorismo, e sem hífen, intraempreendedorismo. **Ano 2007, primeira edição deste evento; ***Ano 2006, este evento começou a ser promovido pela ANPAD, cuja edição foi vigésima quarta. ****Ano 2004, ambos artigos, terceira edição deste evento

Fonte: Elaborado pelos autores com base nos dados pesquisados

Nota-se pela Tabela 2, quatro publicações sobre "empreendedorismo interno" nos eventos temáticos da ANPAD, sendo um artigo sobre "intraempreendedorismo" publicado na primeira edição do EnEPQ em 2007; umsobre "empreendedorismo corporativo" no Simpósio, na primeira promoção desse evento pela ANPAD em 2006; e dois sobre "empreendedorismo corporativo" no EnEO em 2004. 
A predominância da produção sobre empreendedorismo interno está concentrada no principal evento da ANPAD, no caso, sete artigos no EnANPAD. Desses sete artigos, não houve publicações sobre empreendedorismo interno anteriores ao ano de 2003. Assim, organizou-se a Tabela 3 que demonstra a distribuição da quantidade de artigos identificados e selecionados por termo de interesse nesta pesquisa, nos últimos cinco anos (período de 2003 a 2007).

Tabela 3: Ano e Publicações por Termo sobre "empreendedorismo interno" nos EnANPAD

\begin{tabular}{|l|c|c|c|}
\hline \multirow{2}{*}{$\begin{array}{c}\text { Ano do } \\
\text { EnANPAD }\end{array}$} & \multirow{2}{*}{$\begin{array}{c}\text { Quantidade } \\
\text { total }\end{array}$} & \multicolumn{2}{|c|}{ Distribuição de frequências por termo no EnANPAD } \\
\cline { 3 - 4 } & 1 & Intraempreendedorismo* & $\begin{array}{c}\text { Empreendedorismo } \\
\text { corporativo }\end{array}$ \\
\hline 2003 & 1 & 0 & 1 \\
\hline 2004 & 2 & 1 & 0 \\
\hline 2005 & 1 & 1 & 1 \\
\hline 2006 & 2 & 0 & 1 \\
\hline 2007 & 7 & 2 & 0 \\
\hline Total & & $\mathbf{4}$ & $\mathbf{3}$ \\
\hline
\end{tabular}

Fonte: Elaborado pelos autores com base nos dados pesquisados

Na Tabela 3, pressupõe-se que a alta incidência seja em virtude da periodicidade anual desse evento, em relação aos demais que são bianuais $e$ relativamente recentes como promoção da ANPAD. Assim, considerando o levantamento efetuado,optou-se em "abrir mão" de aplicações mais especializadas do método meta-análise, de natureza quantitativa, e procurou-se, a partir da constatação da existência de 11 publicações, descrever a aplicação dos eixos temáticos "intraempreendedorismo" e "empreendedorismo corporativo" nestas pesquisas. Assim, os artigos selecionados para exposição e análise neste trabalho foram apresentados seguindo a codificação e o ordenamento a seguir:

a) (A1) Administração Empreendedora: uma Abordagem Comportamental;

b) (A2) Desenvolvimento da Capacidade Empreendedora de uma Organização; 
c) (A3) Empreendedorismo Corporativo e Comportamento Estratégico: estudo de caso;

d) (A4) A abordagem cognitiva na formação da competência empreendedora, o caso Odebrecht;

e) (A5)Intraempreendedorismo em Organizações Não Governamentais como Prática de Gestão e como Legitimação: Estudo de Caso da ONG REFAZER;

f) (A6) Intraempreendedorismo: um Estudo de Caso sobre o entendimento e a aplicação dos fundamentos organizacionais associados ao termo;

g) (A7) Um estudo sobre a empregabilidade dos funcionários de uma empresa estatal;

h) (A8) Avaliação da Tipologia dos Empreendedores Residentes de Incubadoras Utilizando o Teste "KersyTemperamentSorter": o Caso Incubadora Tecnológica de Santa Maria;

i) (A9) É possível desenvolver habilidades de intraempreendedorismo em estágios supervisionados? Analisando uma proposta de aproximação teórico-empírica;

j) (A10) As estratégias de empreendedorismo corporativo interno por desenvolvimento de mercados e os fatores críticos do sucesso;

k) (A11)Proposição de uma tipologia das subsidiárias estrangeiras no Brasil: resultados de evidências empíricas.

Como critério-chave para discussão complementar dos textos mencionados, procurou-se identificar os comportamentos empreendedores baseado em estudos daUnctad(2008). Essa empresa caracteriza os indivíduos (empregados/stakeholders) em seu espaço de trabalho ou negócio, em termos de: busca de oportunidades e iniciativa, capacidade de correr riscos calculados, exigência de qualidade e eficiência, persistência, comprometimento, busca de informações, estabelecimento de metas, planejamento e monitoramento sistemáticos, persuasão e redes de contatos, independência $e$ autoconfiança. Tais comportamentos empreendedores constituíram as dez categorias de análise discutidas apresentadas no Quadro 1 a seguir: 


\begin{tabular}{|c|c|}
\hline Categorias de análise & Descrição sumarizada \\
\hline $\begin{array}{l}\text { A) Busca de } \\
\text { Oportunidades e } \\
\text { Iniciativa }\end{array}$ & $\begin{array}{l}\text { - Aproveitar oportunidades fora do comum para começar um } \\
\text { negócio, obter financiamentos, equipamentos, terrenos, local } \\
\text { de trabalhos ou assistência; } \\
\text { - Fazer as "coisas" antes de solicitado, ou antes, de ser } \\
\text { forçado pelas circunstâncias; } \\
\text { - Agir para expandir o negócio em novas áreas, produtos ou } \\
\text { serviços; }\end{array}$ \\
\hline $\begin{array}{l}\text { B) Correr Riscos } \\
\text { Calculados }\end{array}$ & $\begin{array}{l}\text { - Avaliar alternativas e calcular riscos deliberadamente; } \\
\text { - Agir para reduzir os riscos ou controlar os resultados; } \\
\text { - Colocar-se em situações que implicam desafios ou riscos } \\
\text { moderados; }\end{array}$ \\
\hline $\begin{array}{l}\text { C) Exigência de } \\
\text { Qualidade e Eficiência }\end{array}$ & $\begin{array}{l}\text { - Encontrar maneiras de fazer "coisas" de uma maneira } \\
\text { melhor, de forma mais rápida, ou com menor custo; } \\
\text { - Desenvolver ou utiliza procedimentos para assegurar que o } \\
\text { trabalho seja terminado a tempo ou que o trabalho atenda a } \\
\text { padrões de qualidade previamente combinados; }\end{array}$ \\
\hline D) Persistência & $\begin{array}{l}\text { - Agir repetidamente ou mudar de estratégia para enfrentar } \\
\text { um desafio ou superar um obstáculo; } \\
\text { - Agir diante de um obstáculo; } \\
\text { - Assumir responsabilidade pessoal pelo desempenho } \\
\text { necessário para atingir metas e objetivos; }\end{array}$ \\
\hline E) Comprometimento & $\begin{array}{l}\text { - Fazer um sacrifício pessoal ou despender um esforço } \\
\text { extraordinário para completar uma tarefa; } \\
\text { - Colaborar com os empregados, colaboradores e parceiros } \\
\text { ou se colocar no lugar deles, se necessário, para terminar um } \\
\text { trabalho; } \\
\text { - Esmerar-se em manter os clientes satisfeitos e colocar em } \\
\text { primeiro lugar a boa vontade em longo prazo, acima do lucro } \\
\text { em curto prazo; }\end{array}$ \\
\hline F) Busca de informações & $\begin{array}{l}\text { - Dedicar-se pessoalmente a obter informações de clientes, } \\
\text { fornecedores e concorrentes; } \\
\text { - Investigar pessoalmente como fabricar um produto ou } \\
\text { fornecer um serviço; } \\
\text { - Consultar especialistas para obter assessoria técnica ou } \\
\text { comercial; }\end{array}$ \\
\hline $\begin{array}{l}\text { G) Estabelecimento de } \\
\text { Metas }\end{array}$ & $\begin{array}{l}\text { - Estabelecer metas e objetivos que são desafiadores e que } \\
\text { têm significado pessoal; } \\
\text { - Definir metas de longo prazo, claras e específicas; } \\
\text { - Estabelecer objetivos de curto prazo, mensuráveis; }\end{array}$ \\
\hline
\end{tabular}

Quadro 1: Características do comportamento empreendedor como categorias analíticas complementares

Fonte: Adaptado de UNCTAD (2008) 


\begin{tabular}{|l|l|}
\hline \multicolumn{1}{|c|}{ Categorias de análise } & \multicolumn{1}{c|}{ Descrição sumarizada } \\
\hline H) Planejamento e \\
$\begin{array}{l}\text { Monitoramento } \\
\text { Sistemáticos }\end{array}$ & $\begin{array}{l}\text { - Planejar dividindo tarefas de grande porte em subtarefas } \\
\text { com prazos definidos; } \\
\text { - Revisar seus planos constantemente, levando em conta os } \\
\text { resultados obtidos e as mudanças circunstanciais; } \\
\text { - Manter registros financeiros e utilizá-los para tomar decisões; }\end{array}$ \\
\hline $\begin{array}{l}\text { I) Persuasão e Redes de } \\
\text { Contatos }\end{array}$ & $\begin{array}{l}\text { - Utilizar estratégias deliberadas para influenciar ou persuadir } \\
\text { ostros; } \\
\text { próprios objetivos; } \\
\text { - Agir para desenvolver e manter relações comerciais; }\end{array}$ \\
\hline $\begin{array}{l}\text { J) Independência e } \\
\text { Autoconfiança }\end{array}$ & $\begin{array}{l}\text { - Buscar autonomia em relação a normas e controles de } \\
\text { outros; } \\
\text { - Manter seu ponto de vista, mesmo diante da oposição ou de } \\
\text { resultados inicialmente desanimadores; } \\
\text { — Expressar confiança na sua própria capacidade de comple- } \\
\text { mentar uma tarefa difícil ou de enfrentar um desafio. }\end{array}$ \\
\hline
\end{tabular}

Quadro 1: Características do comportamento empreendedor como categorias analíticas complementares

Fonte: Adaptado de UNCTAD (2008)

Por meio dessas características, além dos termos "intraempreendedorismo" e "empreendedorismo corporativo", foi realizada uma análise de conteúdo, seguindo a técnica de emparelhamento (BARDIN, 2004), em que os conteúdos textuais expressos nos parágrafos dos artigos selecionados foram relacionados com essas categorias, o que permitiu apontar os resultados desta pesquisa na próxima seção.

\section{Resultados da Pesquisa}

Em um primeiro momento, é preciso observar a limitada quantidade de artigos encontrados sobre a temática. Por essa constatação, infere-se que a produção no campo, no Brasil, é pequena, se tomarmos como referência a ANPAD e ausência no EGEPE, considerando o período analisado. Observou-se, ainda, que os conceitos do intraempreendedorismo $e$ empreendedorismo corporativo, muitas vezes, são confundidos com os conceitos de empreendedorismo. O empreendedorismo parte do pressuposto de que uma pessoa possa abrir seu próprio negócio e o intraempreendedorismo 
refere-se às iniciativas tomadas por funcionários com atitudes empreendedoras dentro de uma organização. Para efeito de organização desta seção, salienta-se que ela foi construída buscando a coesão dos textos em vez da ordem cronológica como será observado no texto dissertado a seguir. O intuito de tal preferência foi o de tornar a leitura dos resultados fluída e agradável.

\section{$5.1($ A1)}

Iniciou-se com o artigo empírico de Pessoa e Gonçalves (2004), já que as autoras propõem uma nova metodologia de ensino da disciplina Administração empreendedora - na Universidade de Brasília - UNB/DF, fundamentada em uma abordagem livre e flexível, baseada em valores de autodidática, condicionando os alunos a criarem seu próprio método de aplicar a disciplina. Em relação ao intraempreendedorismo, as autoras revelam que o objetivo da disciplina é o desenvolvimento do empregado-empreendedor, por meio da aprendizagem dos comportamentos empreendedores.

Para as autoras é vital ao empregado-empreendedor conhecer as diferenças básicas existentes em empreendedorismo e intraempreendedorismo. O não conhecimento dessas diferençastende a resultar em insucessos ao funcionário-empreendedor. Da mesma forma que empreendedores precisam distinguir a ideia de oportunidade em relação ao mercado, os intraempreendedores devem possuir habilidades (pautadas no comportamento empreendedor) para saberem diferenciar ideia de oportunidade dentro da organização em que trabalham. Entretanto, para que esses indivíduos possam atuar de maneira autônoma, a organização em si deve desenvolver um ambiente propício para criar determinadas características em seus colaboradores. Surge, então, a noção de organização empreendedora.

\section{$5.2($ A2)}

Para uma organização ser empreendedora, segundo Cozzi e Arruda (2004), ela precisa ter o sistema de gestão interno bastante flexível, contendo sistemas formais e informais. Tais sistemas devem permitir intensa troca com o ambiente e com fatores exógenos à organização. Quem conduz a performance da empresa, diferentemente das organizações tradicionais, devem ser as pessoas e não a estrutura e as regras. Nesse sentido, a necessidade 
de manter iniciativa individual é latente na empresa, o foco são as atividades-fim e não as atividades-meio, o risco calculado é bem aceito e estimulado, o processo de alocação de recursos é incremental, a chave para estar sintonizado com a captura de novas oportunidades é o conhecimento.

Uma característica peculiar da organização empreendedora é a estrutura organizacional invertida, apresentando poucos níveis hierárquicos. Tal estrutura cria condições para que as tomadas de decisões, concernentes à inovação e à identificação de novas oportunidades, sejam feitas por pessoas e grupos de negócio que estão em constante interação junto aos clientes e ao mercado. Contudo, para se alcançar eficiência essas variáveis devem ser priorizadas na ação organizacional.

O objetivo deste artigo teórico-empírico foi examinar o que seria conhecido sobre a organização empreendedora e o que motivaria as pessoas que nela atuam. Para tanto, foi realizado um estudo de caso no Grupo Gerdau. Esse Grupo foi escolhido porse autodenominar uma empresa empreendedora. Partindo da análise do caso, os autores constataram que o empreendedor corporativo nasce e cresce em organizações com ambientes empresariais com determinadas características de um ambiente empreendedor. A partir do desenvolvimento da pesquisa, os autores confirmaram que o estudo do empreendedorismo corporativo e suas consequências ainda são poucos pesquisados no mundo. Outro fator crítico é que nas organizações, onde predomina o empreendedorismo corporativo, os indivíduos trabalham em busca de um objetivo comum e atuam entrelaçados em um ambiente de cooperação e interdependência, porém não deixam de lado os seus desejos e sonhos individuais, porque as escolhas e os sonhos individuais são colocados em um plano coletivo de construção de um produto maior.

\section{$5.3(\mathrm{A3})$}

Em estudos feitos nas Empresas do Grupo Algar, Uberlândia - MG, no período entre 2001 a 2004, foi conluído que a ação mútua exercida por parte da administração da empresa para determinar a origem de circunstâncias favoráveis no sítio da organização e o comportamento autônomo desenvolvido por funcionários-empreendedores, na empresa citada, tem sido de suma importância para o desenvolvimento do Grupo. De forma que a atitude estratégica autônoma dos colaboradores/empreendedores da Algar constitui um fator preponderante para a definição estratégica corporativa da or- 
ganização. Todavia, quando a administração induz os comportamentos estratégicos nos funcionários, isso gera pouca influência no processo.

A partir dessa realidade, Guimarães e Machado-da-Silva (2006, p. 1) inferem que o empreendedorismo "[...] pode atuar como estratégia corporativa das organizações em resposta às pressões ambientais competitivas, por meio de inovações ou práticas miméticas". O empreendedor corporativo pode atuar nas estratégias de mudanças, bem como no planejamento condicionando equilíbrio para criação de novas ideias, inclusive atuando no melhoramento dos processos já existentes.

\section{4 (A4)}

Ainda sob a noção de empreendedorismo corporativoem organizações privadas, tem-se o artigo A Abordagem cognitiva na formação da competência empreendedora, de Cardoso e Filho (2003), que reuniram dados empíricos que condicionaram uma avaliação de características que proporciona o desenvolvimento da habilidade empreendedora, tangível em organizações de negócios.

A constatação de que o empreendedorismo corporativo tem se tornado uma estratégia de valor relevante para que organizações enfrentem situações duvidosas e contraditórias, os autores desenvolveram um estudo fundamentado na "[...] premissa de que o empreendedorismo corporativo possa ser uma questão de sobrevivência para organizações submetidas a pressões constantes, nos setores dinâmicos da economia" (CARDOSO; FILHO, 2003, p. 3).

Por meio de um caso produzido na Odebrecht Engenharia e Construções, foi descoberto que os empreendedores internos podem ser desenvolvidos internamente por meio deuma metodologia cognitiva, subdividida em etapas de modo que a metodologia se adapte a cada indivíduo. Com o desenvolvimento do empreendedor interno, a empresa incorre em grandes benefícios, pois o progresso de cada indivíduo em superar limites, situações difíceis, proporcionará de uma forma macro e do crescimento da empresa.

$\mathrm{Na}$ Odebrecht, o empreendedorismo corporativo está contido no seu modelo de gestão.

Os gerentes de linha são considerados sócios da empresa, ou seja, eles são dotados de poder para assumir compromissos com clientes e fornecedores por meio de um pro- 
cesso de delegação planejada, no qual tem um domínio praticamente absoluto (CARSOSO; FILHO, 2003, p. 5).

Tais gerentes têm autonomia para definir suas estratégias, correr riscos e trabalhar em projetos. Eles são considerados donos de um negócio da empresa. Para os autores, essa autonomia proporciona um autodesenvolvimento dos colaboradores e gera expectativas positivas em relação ao alcance de cargos superiores. Por terem objetivos maiores, na organização, os funcionários empreendedores trabalham mais, criam mais e se relacionam de forma harmoniosa. Existe uma correlação grande entre atitudes empreendedoras e o crescimento da organização em que o empreendedor corporativo é estimulado.

\section{5 (A5)}

O empreendedor corporativo tem uma grande relevância no terceiro setor também, isso, segundo um estudo feito em uma ONG por Sequeira (2007). O grande motivo para que a autora fizesse um estudo sobre o intraempreendedorismo em ONGs parte do intuito de demonstrar que Organizações Não Governamentais podem utilizar práticas de gestão usadas no intraempreendedorismo. Essa nova forma de gestão, quando realizada de maneira correta, condiciona uma legitimação e sustentabilidade para a organização.

Com o objetivo de identificar a ocorrência efetiva de ações que possam ser associadas ao intraempreendedorismo em ONGs, o autor, Sequeira (2007), concluiu que, em empresas do terceiro setor, podem ser utilizadas práticas correspondentes ao empreendedorismo corporativo. O estudo, em questão, foi feito na ONG Refazer que presta apoio à Criança e ao Adolescente, localizada no Rio de Janeiro. A autora afirma que este estudo é de suma importância para o desenvolvimento de um referencial de análise que possibilite a identificação de aspectos gerenciais e estratégicos do intraempreendedorismo em ONGs. O empreendedor corporativo, quando atua em uma organização do terceiro setor, busca a aquisição e a efetividade no uso dos haveres, o cumprimento de objetivos e a busca pelo melhoramento contínuo da imagem organizacional. 


\section{$5.6(\mathrm{A6})$}

O intraempreendedorismo também pode ser desenvolvido em um banco. Talafirmativa é feita com base no estudo de Chieh e Andreassi (2007) que buscaramanalisar a percepção dos colaboradores de um grande banco brasileiro, acerca de assuntos referentes ao tema intraempreendedorismo corporativo. Houve também uma análise dos fatos que contribuem para o desenvolvimento desse estilo de comportamento na organização.

A pesquisa foi desenvolvida no Unibanco, terceiro maior banco brasileiro, no ano em análise, que atua em praticamente todos os segmentos do mercado financeiro. A organização "[...] tinha um método de gestão até 2004 que era formado a partir da segmentação dos negócios" ( $\mathrm{CHIEH}$; ANDREASSI, 2007, p. 5).Internamente, cada uma dessas áreas, conhecidas como pilares, tinha sua estrutura hierárquica praticamente independente das demais. A partir do mesmo ano, houve uma alteração da estrutura organizacional. Estabeleceu-se uma única presidência culminando em uma redução de níveis hierárquicos, o que contribuiu para a consolidação de áreas de suportes e de administração, proporcionando maior eficiência e maior sinergia na firma.

Para se inferir que o intraempreendedorismo é aplicável ao Unibanco, os autores, por meio de entrevistas feitas junto aos indivíduos da organização, constataram que a empresa utiliza-se de mecanismos formais que incentivam o intraempreendedorismo. Também foi descoberto que a prática do comportamento intraempreendedor na empresa é utilizada de forma estratégica. Tais estímulos permitem concluir que os gerentes do banco são orientados a dar valor e a dar atração aos funcionários intraempreendedores. Uma característica que faz do Unibanco um estimulador do intraempreendedora é o fato de os funcionários poderem usufruir de diversos programas de premiação, o que condiciona um reforço às condutas e às atitudes intraempreendedoras.

Pode-se concluir, através do estudo de caso realizado no Unibanco, que a organização de uma maneira geral é intraempreendedora. Uma limitação existente é a de que um banco normalmente tem seus processos muito bem detalhados e burocráticos impedindo, às vezes, o uso da criatividade e da inovação, por parte do colaborador. Entretanto, outros conceitos do empreendedorismo corporativo podem ser usados de forma razoável nesse tipo de organização. A atitude proativa, o senso de propriedade e o fato do 
funcionário ser protagonista no processo são características do comportamento intraempreendedor.

\section{7 (A7)}

O intraempreendedorismo tem se evidenciado em todos os setores da economia. Já foram mencionados, neste estudo, o empreendedorismo interno em empresas do segundo e do terceiro setor. Agora, surge a questão de como seria o comportamento intraempreendedor em uma organização do primeiro setor?

Referente a tal especulação, deduz-se, a partir do artigo Um estudo sobre a empregabilidade dos funcionários de uma estatal, desenvolvido pelas autoras Zimmer e Hoeltgebaum (2004) que é possível implantar o empreendedorismo corporativo em uma organização pública. Por meio de uma pesquisa aprofundada, as autoras identificaram habilidades intraempreendedoras nos funcionários de uma estatal que aderiram a um programa de dispensa incentivada. Tal método contribuíra para o desenvolvimento da empregabilidade dos indivíduos. O objetivo do estudo é salientar o grande desafio do profissional do Século XXI, em se manter em um nível elevado de empregabilidade. As autoras traçam prerrogativas existentes no trabalhador privado em detrimento do trabalhador público. Assim, a questão norteadora deste artigo evoca se os funcionários concursados verdadeiramente são os mais indicados para auferirem a solidez advinda das diretrizes que predominam nas organizações do estado.

Para as pesquisadoras, é duvidosa a relação entre estabilidade de emprego e esforço para se fazer um trabalho de qualidade. $\mathrm{O}$ artigo levanta a hipótese de que para a organização pública se tornar competitiva é preciso desenvolver em sua massa crítica habilidades encontradas em organizações privadas. Para tanto, a visão, por parte da liderança, com relaçãoàs pessoas que trabalham na organização, deve ser um tanto quanto diferente. Segundo a literatura do campo, as organizações tornam-se bem-sucedidas quando não consideram seus funcionários como meros remunerados. Essas organizaçõesse tornam bem-sucedidas quando consideram seus indivíduos como colaboradores e parceiros de negócio.

Para que as organizações se adaptem às mudanças é de suma importância que "[...] seus colaboradores sejam preparados para lidar com essas variações, tanto no aspecto pessoal, como no profissional" (ZIMMER; 
HOELTGEBAUM, 2004). Contudo, o desenvolvimento das pessoas internas na organização está no desafio. Cada funcionário deve ser capaz de identificar oportunidades viáveis no mercado para o beneficiamento da organização em que está inserido, tomar conhecimento de quais habilidades intraempreendedoras serão exigidas pelo seu empregador, tornar-se um trabalhador comprometido com a organização. Conclui-se que a organização pública tornar-se-á mais competitiva adotando medidas que impulsionam seus indivíduos a serem intraempreendedores. As habilidades adquiridas serão de suma importância para o desenvolvimento organizacional.

\section{8 (A8)}

Há casos em quea relação empreendedorismo/empreendedorismo corporativo é latente. Um exemplo de organização em queháessa relação são as incubadoras de empresas. No estudo feito por Mallmann, Borba e Ruppenthal (2005), em que foi realizada uma análise do perfil dos empreendedores residentes da Incubadora Tecnológica da Universidade Federal de Santa Maria, identificou-sepor meio do Teste KeirseyTemperament Sorter que a maioria dos indivíduos da organização apresenta características contidas no perfil empreendedor indicado pela literatura. Os residentes da Incubadora são orientados para resultados, são comprometidos, simpatizam pela agressividade, o planejamento e o controle são inerentes a eles. Somado a isto, existe um incentivo à inovação e à criatividade. Nesse sentido, percebese que esse incentivo proporciona maior autonomia ao residente, desenvolvendo um perfil intraempreendedor no indivíduo. Outro motivo pelo qual a maioria dos indivíduos da incubadora estudada apresenta características intraempreendedoras é o fato de existir exigência, por parte do plano de negócios, de tais habilidades, já no processo seletivo do ingresso na incubadora.

\section{9 (A9)}

O nono artigo trata sobre as possibilidadesdedesenvolver habilidades intraempreendedoras em estágios supervisionados(CÂMPELO; ALMEIDA, 2007). O estágio Supervisionado, para os pesquisadores, é apontado como uma ponte que une o academicismo à política empresarial. No estágio, o indivíduo pode progredir em suas atitudes empreendedoras por meiodo contato do estudante com a prática profissional. Com intuito de impulsionar o acadê- 
mico a desenvolver a prática profissional, o Estágio Supervisionado proporciona ao iniciante uma maior vivência com o mundo empresarial, através do exercício do cotidiano da organização, havendo a possibilidade desse estudante exercitar conhecimentos intrinsecamente ligados à sua formação, antecipando o desenvolvimento de habilidades, desconhecidas até o momento.

\section{$5.10(\mathbf{A 1 0})$}

Para Garcez e Sbragia (2006), o empreendedorismo corporativo é um processo constituído de inúmeras situações que têm por meta explorar os comportamentos e as atitudes empreendedoras através do estímuloda cultura empreendedora, o aprendizado organizacional e o gerenciamento da inovação no ambiente interno da organização. Tais características são incentivadas com o intuito de alcançar o desenvolvimento de novas combinações de insumos e a criação e administração de novos negócios dentro da empresa. O empreendedor interno tem papel importante nesse processo de criação $e$ administração de novos negócios corporativos, pois ele é um dos determinantes para as estratégias de crescimento e à entrada em novos negócios. Segundo os autores, o empreendedor corporativo pode ser desenvolvido em vários níveis da corporação, porém seu raio de atuação é limitado de acordo com a sua função.

O objetivo de desenvolver o empreendedor interno é transformar funcionários/colaboradores pragmáticos em indivíduos capazes de criar novos produtos/processos. A criatividadeé estimulada a partir da criação de entidades organizacionais inseridas no ambiente corporativo, como novos pilares e unidades estratégicas de negócio, que englobam as estratégias necessárias para o desenvolvimento interno de produtos ou de mercados.

\section{$5.11(\mathbf{A 1 1})$}

Em estudo realizado com base no universo das 1.000 maiores empresas multinacionais de capital estrangeiro que atuam no Brasil, os autores Borini, Júnior e Guevara (2005) atestam que o desenvolvimento do intraempreendedorismo é de suma importância para a competitividade das subsidiárias estrangeiras presentes no país. As variáveis que compõem os fatores que caracterizam as subsidiárias intraempreendedoras são: assumir o risco com atributo positivo; incentivara tomada de decisão com risco calcula- 
do; a alta direção possuir experiência com atividades de inovação; apoiar decisões de risco individual; e obter apoio da alta direção para atividades empreendedoras.

A análise dos artigos proporcionou uma identificação de características do comportamento empreendedor no contexto do empreendedorismo interno, auxiliando na construção do Quadro 2. Esse Quadro revela que características do comportamento empreendedor como busca de oportunidades e iniciativa, busca de informações e iniciativa e independência e autoconfiança foram predominantes durante a análise das publicações demonstrando serem características comuns tanto em intraempreendedores quanto em empreendedores corporativos.

\begin{tabular}{|c|c|c|c|c|c|c|c|c|c|c|c|}
\hline \multirow{2}{*}{$\begin{array}{l}\text { Características do } \\
\text { comportamento } \\
\text { empreendedor }\end{array}$} & \multicolumn{11}{|c|}{ Artigos } \\
\hline & $\begin{array}{l}\text { A1 } \\
\text { (IE) }\end{array}$ & $\begin{array}{l}\text { A2 } \\
\text { (EC) }\end{array}$ & $\begin{array}{c}\text { A3 } \\
\text { (EC) }\end{array}$ & $\begin{array}{l}\text { A4 } \\
(\mathrm{EC})\end{array}$ & $\begin{array}{l}\text { A5 } \\
\text { (IE) }\end{array}$ & $\begin{array}{l}\text { A6 } \\
\text { (IE) }\end{array}$ & $\begin{array}{l}\text { A7 } \\
\text { (EC) }\end{array}$ & $\begin{array}{l}\text { A8 } \\
\text { (EC) }\end{array}$ & $\begin{array}{l}\text { A9 } \\
\text { (IE) }\end{array}$ & $\begin{array}{l}\text { A10 } \\
\text { (EC) }\end{array}$ & $\begin{array}{r}\text { A11 } \\
\text { (IE) }\end{array}$ \\
\hline Busca de oportunidades e iniciativa & $\mathrm{x}$ & $\mathrm{x}$ & $\mathrm{x}$ & $\mathrm{x}$ & $\mathrm{x}$ & $\mathrm{x}$ & $\mathrm{x}$ & $\mathrm{x}$ & $\mathrm{X}$ & $\mathrm{X}$ & $\mathrm{x}$ \\
\hline Correr riscos calculados & $\mathrm{X}$ & $\mathrm{X}$ & & $\mathrm{X}$ & & & $\mathrm{X}$ & & & $\mathrm{X}$ & $\mathrm{X}$ \\
\hline Exigência de qualidade e eficiência & $\mathrm{X}$ & $\mathrm{X}$ & $\mathrm{X}$ & $\mathrm{X}$ & $\mathrm{X}$ & $\mathrm{X}$ & $\mathrm{x}$ & & & & $\mathrm{x}$ \\
\hline Persistência & $\mathrm{X}$ & & & $\mathrm{X}$ & & & $\mathrm{X}$ & & & & \\
\hline Comprometimento & $\mathrm{X}$ & $\mathrm{X}$ & & & $\mathrm{X}$ & $\mathrm{X}$ & $\mathrm{X}$ & $\mathrm{X}$ & $\mathrm{X}$ & & \\
\hline Busca de informações e iniciativa & $\mathrm{X}$ & $\mathrm{X}$ & $\mathrm{X}$ & $\mathrm{X}$ & $\mathrm{X}$ & $\mathrm{X}$ & $\mathrm{X}$ & & $\mathrm{X}$ & $\mathrm{X}$ & $\mathrm{X}$ \\
\hline Estabelecimento de metas & $\mathrm{X}$ & & & $\mathrm{X}$ & & $\mathrm{X}$ & & $\mathrm{x}$ & & & $\mathrm{X}$ \\
\hline $\begin{array}{l}\text { Planejamento e monitoramento } \\
\text { sistemáticos }\end{array}$ & $\mathrm{X}$ & $\mathrm{X}$ & $\mathrm{X}$ & & $\mathrm{X}$ & & & $\mathrm{x}$ & $\mathrm{X}$ & & \\
\hline Persuasão e redes de contatos & $\mathrm{X}$ & $\mathrm{X}$ & & & $\mathrm{X}$ & & $\mathrm{X}$ & $\mathrm{X}$ & $\mathrm{X}$ & & \\
\hline Independência e autoconfiança & $\mathrm{X}$ & $\mathrm{X}$ & $\mathrm{X}$ & $\mathrm{X}$ & $\mathrm{X}$ & $\mathrm{X}$ & $\mathrm{X}$ & $\mathrm{X}$ & $\mathrm{X}$ & $\mathrm{X}$ & $\mathrm{X}$ \\
\hline
\end{tabular}

Legenda: (IE) - Intraempreendedorismo; (EC) - Empreendedorismo Corporativo.

Quadro 2: Identificação das características do comportamento empreendedor nos artigos estudados

Fonte: Elaborado pelos autores com base nos dados pesquisados

Entretanto, ao resgatar a diferença conceitual entre intraempreendedores e empreendedores corporativos, apresentada no início deste metaestudo, que reside no horizonte de atuação em virtude do cargo ou da posição em que o indivíduo ocupa na organização, percebe-se com o Quadro 2 que esse argumento ganha potencialmente duas evidências empíricas significativas obtidas com a análise dos artigos para sustentá-lo. O primeiro indica que o comportamento "correr riscos calculados" parece mais presente nos trabalhos sobre empreendedorismo corporativo do quenos sobre intraempreendedores. 
E o segundo demonstra que o "comprometimento" é mais latente em trabalhos sobre intraempreendedorismo do que naqueles acerca de empreendedorismo corporativo.

Há também uma relação interessante entre a baixa frequência de determinadas características do comportamento empreendedor e asbarreiras na prática do empreendedorismo interno nas organizações. Os comportamentos empreendedores que obtiveram menor frequência, conforme Quadro 2, foram: persistência; estabelecimento de metas; e persuasão e redes de contatos. Pressupõe-se que a baixa evidenciação desses comportamentos empreendedores não quer dizer que eles não existam, mas sim que não foram identificados na análise do conteúdo dos artigos selecionados. Contudo, essa baixa frequência está associada aos entraves na prática do empreendedorismo interno nas organizações identificados na análise dos 11 artigos, são eles: rigidez dos processos de aprovação e decisão; gerências centralizadoras; alta formalização do processo de trabalho; falta de espírito de equipe; delimitações impostas pelas descrições de cargo; obediência irrestritas às normas e padrões internos; pouca ou nenhuma tolerância a erros e fracasso; $e$ falta de orçamento para empreendimentos de risco.

\section{Conclusão}

A atuação do empreendedor interno revela-se uma discussão relevante para o desenvolvimento das organizações. Para entender melhor essa afirmação é necessário compreender a relação organização/indivíduo, não somente pela literatura sobre comportamento organizacional, mas também pela literatura sobre empreendedorismo interno. Observou-se neste estudo que o empreendedor interno é um agente que propicia maior sinergia para a organização. Esse indivíduo busca a transformação de ideais individuais em ações coletivas por meiodo gerenciamento de incertezas no seu espaço de trabalho.

Este artigo demonstrou que ao estudar o empreendedorismo interno é preciso considerar o ambiente de atuação do indivíduo, inclusive a existência de um clima organizacional favorável ao estímulo e ao desenvolvimento de empreendedores internos, cabendo aos proprietários ou dirigentes da organização tal responsabilidade.

Observa-se que a ação dos empreendedores internos pode ser verificada em todos os setores da economia. A título de ilustração, no setor 
público, o Governo de Minas Gerais tem adotado a noção de empreendedor interno em sua gestão. $\mathrm{O}$ governo mineiro percebeu que possuir pessoas com comportamentos empreendedores dentro de sua estrutura traria grandes benefícios para o Estado. Assim, o governo mineiro instituiu o cargo de empreendedor público. Esse cargo tem como objetivo recrutar pessoas capacitadas para desenvolver projetos em prol da administração do estado (VALADARES et al., 2010).

Com relação ao entendimento do termo empreendedorismo interno $e$ os eixos temáticos associados a ele, pode-se dizer que o termo, no sentido literal, ainda é pouco conhecido e utilizado pela comunidade científica. Os estudos sobre empreendedorismo no Brasil é ainda focado nos empreendedores de negócios, na figura do criador de empresas ou de organizações sociais. Dessa forma, existe um espaço ávido para o desenvolvimento de estudos sobre empreendedorismo nas organizações no Brasil e possivelmente no exterior.

Foram encontradas particularidades na aplicação empírica doseixos temáticos estudados. O intraempreendedorismo e o Empreendedorismo Corporativo apresentam características próprias e quando analisados com método e referencial analítico explicitam ainda mais esses sentidos diferentes, que reforçam a distinção sutil entre os termos, mas pertinente para o uso adequado deles nos estudos no campo.

Observa-se, a partir dos resultados de pesquisa, que na medida em que a organização cresce, a prática e as discussões sobre "empreendedorismo interno" tendem a ser segmentadas em dois tipos, o intraempreendedorismo e o empreendedorismo corporativo. Assim, é preciso que os estudiosos acerca do empreendedorismo interno estabeleçam critérios rigorosos para poder distinguir adequadamente com que tipo está tratando em suas pesquisas. Desta forma, possíveis equívocos conceituais poderão minimizados. Observou-se também que, se a organização é de pequeno porte, o trabalho do empreendedor interno é orientado para inovações internas, ou seja, o trabalho é focado nos processos, atividades operacionais com o objetivo de tornálas mais efetivas e ágeis. Quando a organização assume a categoria de médio e/ou grande porte, o empreendedor interno comporta-se de forma mais estratégica para a organização. Nesse sentido, o trabalho deste indivíduo é focado no ambiente externo da organização, ou seja, seu olhar está voltado para o longo prazo da organização. Assim ele procura aumentar os níveis de 
competitividade da organização, isto é, o trabalho do empreendedor interno é orientado para inovações externas.

Desse modo, este trabalho contribui com um panorama dos caminhos das pesquisas publicadas sobre o Empreendedorismo interno no Brasil em eventos especializados da área de administração, no período de 1997 a 2007. Acredita-se que essa contribuição auxiliará no desenvolvimento de futuras discussões acerca do intraempreendedorismo e o empreendedorismo corporativo no campo. Diante disso, como resultado complementar, esta pesquisa encontrou um contorno de proposta científica mais empiricistadoque de construção teórica e uma feição metodológica porestudos de caso com algumas pretensões de construção indutiva de conhecimento. A orientação e a estratégia de pesquisa podem ser aperfeiçoadas com a utilização de outros métodos de coleta e análise de dados de natureza tanto qualitativa quanto quantitativa.

Conclui-se que o período de 1997 a 2007 no Brasil, a produção científica sobre empreendedorismo interno foinula nas edições do EGEPE e baixa nos eventos da ANPAD, já que somente 11 trabalhos foram identificados por meio dos eixos temáticos intraempreendedorismo e empreendedorismo corporativo. Desse modo, não é possível inferir sobre a dominância na produção científica do campo de um termo ou eixo temático sobre o outro, pois eles são quantitativamente próximos, cinco trabalhos sobre intraempreendedorismo e seis sobre empreendedorismo corporativo. Contudo, nota-se uma tendência de crescimento na produção sobre esses assuntos ao considerar os últimos dois anos, 2006 e 2007.

Todavia, a restrita produção científica nacional sobre "empreendedorismo interno" pode ser justificada pela recente importância dada a ela, nos últimos anos, em especial, nos anos de 2006 e 2007, nos eventos da ANPAD. Isso reforçaria a presença de material bibliográfico estrangeiro e descontextualizado no Brasil, refletindo na ausência de literatura sobre o tema considerando as particularidades e as regionalidades encontradas em nosso país. Porém, será essa baixa produção sobre esses eixos temáticos exclusiva da ANPAD e do EGEPE e do Brasil? Como estão sendo abordados e aplicados esses eixos em outros eventos relacionados à área de Empreendedorismo em outros países? E nas publicações e eventos científicos internacionais? Será que existe congruência no tratamento científico (como autores mais utilizados, métodos de pesquisa aplicados, resultados alcançados etc.) desses eixos entre as esferas nacional e internacional? Eis algumas provocações que 
podem nortear futuras pesquisas no campo, queapenas foram possíveis a partir das evidências apontadas neste artigo sobre a construção do conhecimento em "empreendedorismo interno". Isso torna evidente a necessidade de se aplicar este termo nas pesquisas científicas para propor avanços nos estudos sobre empreendedorismo, assim como nos eixos temáticos que o evidencia nas organizações, como foi discutido neste trabalho através dos termos intraempreendedorismo e empreendedorismo corporativo.

Pode-se acrescentar que pela diversidade de organizações em que o empreendedor interno pode estar, o mesmo pode ser desenvolvido por um rol de comportamentos empreendedores (UNCTAD, 2008). Nota-se que o espaço de pesquisa é amplo e fértil. Considerando que o empreendedor interno tem papel relevante no desenvolvimento da organização em que atua, enfatiza-se a importância de uma reflexão profunda em torno do Intraempreendedorismo, seja em estudos qualitativos, seja em estudos quantitativos, sejam em abordagens críticas, seja em abordagens pragmáticas. Somente através de uma visão macro no que tange ao tema intraempreendedorismo e seus impactos na realidade organizacional, poderse-á questionar formas de desenvolvimento do empreendedor interno impostas atualmente e propor outras possibilidades que tragam melhores resultados.

\section{Reflections end Perspectives Concerning the Construction of Knowledge about Indoor Entrepreneurship}

\section{Abstract}

This study searches to bring out the scientific production in the specialized events in Brazil concerning the meaning of indoor entrepreneurship in the field of business administration from 1997 to 2007, intending to identify the construction of knowledge and the emerging perspectives in researches about this focus on the field. Aiming at complementing, it also searched to identify the characteristics of the indoor entrepreneur's behavior, in the mentioned and selected scientific production. The principles of meta-analysis of content were used. Among the main results, it is observed, as reflections needed in the field, the necessity to clarify the elements that distinguish corporative entrepreneurs from the intra entrepreneurs in the organizations. As future perspectives of investigation, there is a vast field to explore in theoretical and empirical terms the singularities of the manifestation in 
contemporary organizations of indoor entrepreneurship in Brazil in a comparative perspective.

Key words: Meta-analysis. Intra entrepreneurship. Corporate entrepreneurship.

\section{Referências}

ALBERNETHY, A. M.; FRANKE, G. R. The information content of advertising: a meta-analysis. Journal of Advertising, v. 25, n. 2, p. 1-17. Minneapolis: American Academy of Advertising, 1996,

ANTONCIC, B.; HISRICH, R. D. Intrapreneurship: Construct refinement and crosscultural validation, Journal of Business Venturing, v. 16, p. 495-527, EUA, 2001.

ANTONCIC, B.; HISRICH, R. D. Privatization, Corporate entrepreneurship andperformance: Testing a normative model.Journal of Developmental Entrepreneurship, v. 8, n. 3, p. 197-218, EUA, dez./2003.

BARDIN, L. Análise de Conteúdo. 3.ed. Lisboa: Edição 70, 2004.

BORINI, F. M.; JÚNIOR, M. de M. O.; GUEVARA, A. J. H. Proposição de uma Tipologia das Subsidiárias Estrangeiras no Brasil: Resultados de Evidências Empíricas. In: ENCONTRO DA ASSOCIAÇÃO NACIONAL DE PÓS-GRADUAÇÃO EM ADMINISTRAÇÃO, 29. Anais. Brasília. EnANPAD. 2005. CD.

BURGELMAN, R. A.; SAYLES, L. R. Inside corporate innovation strategy, structure and managerial skills. New York: The freepress, 1986.

CÂMPELO, A. F; ALMEIDA, A. M. B. É possível desenvolver habilidades de Intra-empreendedorismo em estágios supervisionados? Analisando uma proposta de aproximação teórico-empírica. In: ENCONTRO DE ENSINO E PESQUISA EM ADMINISTRAÇÃO E CONTABILIDADE, 1, Anais. Recife. EnEPQ/ ANPAD. 2007. CD.

CARDOSO, O. de O.; FILHO, U. B. A abordagem cognitiva na formação da competência empreendedora: caso da Odebrecht. In: Encontro da Associação Nacional de Pós-Graduação em Administração, 27. Anais. Atibaia: EnANPAD/ ANPAD. 2003. CD. 
CHIEH, N.; ANDREASSI, T. Intra-empreendedorismo: um estudo de caso sobre o entendimento e a aplicação dos fundamentos organizacionais associados ao termo. In: Encontro da Associação Nacional de Pós-Graduação em Administração, 31. Anais. Rio de Janeiro. EnANPAD/ANPAD. 2007. CD.

CHUNG, L. H.; GIBBONS, P. T. Corporate entrepreneurship: The roles of ideology and social capital. Group \& Organization Management, v. 22, n. 1, p. 10-30, March 1997.

COOPER, A. C. EntrepreneurialEnvironment. Industrial Research, p. 74-76, set. 1970 .

COVIN, J. G.; COVIN, T. Competitive aggressiveness, environmental context and small firm performance.Entrepreneurship Theory \& Practice, v. 14, n. 4, p. 35-50, EUA, s.d. 1990.

COZZI, A.; ARRUDA,C. Desenvolvimento a capacidade empreendedora de uma organização. In: Encontro de Estudos Organizacionais, 3. Anais. Atibaia. EnEO/ANPAD. 2004. CD.

CUNNINGHAM, J. B.; LISCHERON, J. Defining Entrepreneurship. Journal of Small Business Management, 1991.

DESS, G. G.; LUMPKIN, G. T.; COVIN, J. G. Entrepreneurial strategy making and firm performance: Tests of contingency and configurational models.

Strategic Management Journal, v. 18, n. 9, p. 677-695, EUA, 1997.

ELLIS, J. R.; TAYLOR, N. T. Specifying entrepreneurship. Frontiers of entrepreneurship research. Wellesley, MA: Babson College, p. 527-542, 1987.

EMMENDOERFER, M. L. et al. Esforços para a construção do conhecimento sobre empreendedorismo interno: reflexões e perspectivas a partir de eventos da ANPAD (1997-2007). In: SIMPÓSIO DE GESTÃO DA INOVAÇÃO TECNOLÓGICA, 25. Anais... Brasília (DF). SIMPÓSIO/ANPAD. 2008. CD.

EMMENDOERFER, M. L.; VALADARES, J. L; HASHIMOTO,M. Evidências do Empreendedorismo interno em organizações no contexto da Inovação. Revista Eletrônica de Ciência Administrativa (RECADM), v. 9, n. 2, p. 144-156, nov./2010, 
EPSTEIN, J. H. Making Sense of Science: the rise of meta-analysis. Book review. The Futurist, v. 32, n. 2, p. 44-45, 1998.

FERREIRA, J. Corporate entrepreneurship: a strategic and structural perspective. New England Journal of Entrepreneurship, p.59-71, 2001.

GARCÊS, Marcos G; SBRAGIA, Roberto. As Estratégias de Empreendedorismo Corporativo Interno por Desenvolvimento de Mercados e os Fatores Críticos do Sucesso. In: ENCONTRO DA ASSOCIAÇÃO NACIONAL DE PÓS-GRADUAÇÃO EM ADMINISTRAÇÃO, 30. Anais. Salvador. EnANPAD. 2006. CD.

GUIMARÃES, T. B. C.; MACHADO-DA-SILVA, C. L. Empreendedorismo corporativo e comportamento estratégico: estudo de caso. In: Simpósio de Gestão da Inovação Tecnológica, 24. Anais. Gramado. SIMPÓSIO/ANPAD. 2006. CD.

HASHIMOTO, M. Espírito Empreendedor nas organizações: aumentando acompetitividade através do intra-empreendedorismo.São Paulo: Saraiva, 2006.

HASHIMOTO, M. Organizações Intra-empreendedoras: Construindo a ponte entre clima interno e desempenho superior. $363 \mathrm{f}$. (Tese de doutorado). EAESP/ FGV, São Paulo, junho, 2009.

HISRICH, R. D.; PETERS, M. P. Empreendedorismo. 5. ed. Porto Alegre: Bookman, 2004.

HUNT, M. How Science Takes Stock. New York: Russell Sage Foundation, 1997.

JONES, G. R.; BUTLER, J. E. Managing internal corporate entrepreneurship: an agency theory perspective. Journal of Management, v. 18, n. 4, p. 733749, EUA, 1992.

KHANDWALLA, P. N. Generators of pioneering-innovative management: some indian evidence. Organization Studies, EUA, v. 8 n. 1, p. 39-59, 1987.

LONGENECKER, J.; SCHOEN, J. E. The essence of entrepreneurship. Journal of small business management. EUA, 1975.

LUMPKIN, G. T.; DESS, G. G. Clarifying the entrepreneurial orientation construct and linking it to performance. Academyof Management Review, v. 21, n. 1,p. 135-172, 1996. 
MALLMANN, T. D. M; BORBA, B. W; RUPPENTHAL, J. E. Avalização as tipologia dos empreendedores residentes de incubadoras utilizando o teste Kersey Temperament Sorter. O caso da incubadora tecnológica se Santa Maria. In: Encontro da Associação Nacional de Pós-Graduação em Administração, 29. Anais... Brasília: EnANPAD/ANPAD. 2005. CD.

MILLER, A.; CAMP, B. Exploring determinants of success in corporate venture. Journal of Business Venturing, EUA, v. 1, n. 1, p. 87-105, 1985.

MORSE, E. A. Current thought in firm level entrepreneurship. Western Academy of Management meeting, EUA, 1996.

NICHOLAS, T. Secrets of entrepreneurial leadership. USA: Enterprise Dearborn, 1993.

PESSOA, E.; GONÇALVES, S. M. G. Administração empreendedora: uma abordagem comportamental. In: Encontro da Associação Nacional de PósGraduação em Administração, 28. Anais. Curitiba. EnANPAD/ANPAD. 2004. CD.

PINCHOT III, G. Intrapreneuring: porque você não precisa deixar a empresa para tornar-se um empreendedor. São Paulo: Harbra, 1985.

PRYOR, A. K.; SHAYS, E. M. Growing the business with intrapreneurs. Business Quarterly, London, 1993.

SATHE, V. Fostering entrepreneurship in large, diversified firm.

Organizational Dynamics, EUA, v. 18, n. 1, p. 20-32, 1989.

SCHOLLHAMMER, H. N. Internal corporate entrepreneurship. In: KENT, C.; SEXTON, D.; VESPER, K. (Ed.), Encyclopedia of entrepreneurship. p. 209-223, Englewood Cliffs, NJ: Prentice Hall, 1982.

SEIFFERT, P. Q. Empreendendo novos negócios em corporações. São Paulo: Atlas, 2005.

SEQUEIRA, S. V. Intra-empreendedorismo em organizações não-governamentais como prática de gestão e como legitimação: estudo de caso da ONG REFAZER. In: Encontro da Associação Nacional de Pós-Graduação em Administração, 29.Anais... Brasília: EnANPAD/ANPAD. 2005. CD. 
STEVENSON, H. H.; JARILLO, J. C. A paradigm of entrepreneurship:

Entrepreneurial management. Strategic Management Journal, EUA, v. 11, p. 17-27, 1990.

UNCTAD - UNITED NATIONS CONFERENCE ON TRADE AND

DEVELOPMENT. Empretec. On-line. Disponível em: < http:// www.unctad.org >. Acesso em: $1^{\circ}$, jun. 2008.

VALADARES, J. L. et al. Modernização da Administração Pública de Minas Gerais: um Estudo exploratório do Cargo de Empreendedor Público. In: Encontro da Associação Nacional de Pós-Graduação em Administração, 34. Anais. Rio de Janeiro. EnANPAD/ANPAD. 2010. CD.

ZAHRA, S. A. Predictors and financial outcomes of corporate entrepreneurship: An exploratory study. Journalof Business Venturing. EUA, v. 6, p. 259-285, 1991.

ZIMMER, P.; HOELTGEBAUM, M. Um estudo sobre a empregabilidade dos funcionários de uma estatal. In: Encontro de Estudos Organizacionais, 3, Anais... São Paulo: EnEO/ANPAD, 2004. CD. 